\title{
How to Establish an Early Warning System: Concept and First Steps in Switzerland
}

\author{
Andreas V. Kohlschütter and Günther Bächler
}

\begin{abstract}
The authors introduce a pilot project on a general conflict warning system mainly designed to serve the Swiss Foreign Ministry. Especially after the $R$ wanda disaster, the administration (backed by the Foreign Committee of the Parliament) underlines the need for $a$ computerized system that builds the ground for early recognition and, thus, enhances the "institutionalized" pressure to (re)act in a stage of a conflict as early as possible. Questions arise on the state of the art as well as on the interface between early warning on one hand and decision making and early action on the other.
\end{abstract}

\section{Précis}

Les auteurs proceddent da la description introductoire d'un projet-pilote de prévention de conflit généralisé visant principalement a desservir le Ministère Suisse des Affaires Etrangères. Parti-

Andreas Kohlschütter is Senior Fellow at the Swiss Peace Foundation in Berne. He was Editor and diplomatic correspondent of the German weekly newspaper Die Zeit (Hamburg). Among his many other distinguished posts are spokesperson and information director of Prince Sadruddin Aga Khan, UN Coordinator for Humanitarian and Economic Assistance to Afghanistan, Head of the OSCE-Mission to Ukraine, Advisor to the Swiss Foreign Minister and Chairman in Office of OSCE. He also worked with the Refugee Elections Steering Group for Bosnia and Herzegovina Elections in 1996.

Günther Baichler is Director of the Swiss Peace Foundation in Bern. In 1996-1997 he was a Research Associate at the Center for Science and International Affairs, JFK School, Haroard University. His research covers the Democratization of Security Policy, Environmental Transformation and Violent Conflicts, Conflict Management (Mediation), and Preoentive Diplomacy.

Paper presented at Synergy in Early Warning Conference, March 14-17, 1997, Westin Harbour Castle, Toronto, Canada. culièrement après la catastrophe du Rwanda, l'Administration (appuyée par le Comité aux Affaires Etrangères du Parlement) met l'emphase sur la nécessité d'un système informatisé jettant les bases d'une procédure de reconnaissance préventive, et de fait amplifie les pressions "institutionnelles" favorisant une (ré)action survenant le plus tôt possible dans un conflit donné. Des questions sont soulevées concernant l'effet de mode relié à ce genred'initiative, et concernant l'interface entre l'alerte préventive d'un côté et la prise de décision liée à l'action rapide de l'autre.

In this paper we introduce the framework and initial outline of a pilot project on an early warning system ("FAST") designed to serve the Swiss Foreign Ministry. After the disaster of Rwanda (which affected a strongpoint of Swiss Development Cooperation) the Swiss Foreign Ministry, backed by the Foreign Affairs Committee of Parliament, underlined the need for an early warning system.

- In view of disposing of an instrument for effective preventive diplomacy, enabling the Swiss administration to recognize and act upon a crisis as early as possible and at the same time enhancing the "institutionalized pressure" for such early decision making;

- in view also of the fact that-in Switzerland as well as other OECD states-an ever increasing part of the available development aid is being consumed by disaster and costly post-conflict emergency requirements which could be considerably reduced by early preventive action.

Three different sections of the Swiss Foreign Ministry (General Secretariat, Peace Policies and OSCE, Development Cooperation) are interested in an early warning system, that focuses on monitoring, analysis, planning and policy options in the framework of preventive diplomacy. It is thus understood that the interface between early warning and early action and political decision making is as crucial as the overall design of an early warning system itself.

The mandate that the Swiss Peace Foundation received for drafting the pilot project contains the following major requests:

- to "explore the preconditions, the efficiency and the costs of FAST (German abbreviation for: "Early Recognition of Tensions and Fact Finding") as an instrument to prepare decisions in preventive diplomacy;"

- to provide an overview of existing capacities and services in the field of early warning;

- to explore possible cooperation with existing institutions in this field;

- to formulate proposals concerning an adequate set of early warning indicators;

- to evaluate software packages, networks, WWW-based systems, etc. for the purpose of structuring an early warning system;

- to design a minimal capacity concept for FAST in the framework of an early warning system; and

- to define the necessary manpower and financial requirements, like profile of staff members, size of permanent staff, annual costs (minimal requests) and other institutional aspects:

An effective early warning system is a part of and a precondition for effective preventive diplomacy, defined in the narrower sense of crisis avoidance or pre-conflict prevention rather than in the more general terms of in-conflict or post-conflict crisis management. 
Any attempt to set up and implement an early warning mechanism for the Swiss Foreign Ministry has therefore to take into account the inherent impediments that tend to slow down or exclude preventive diplomatic action.

At the UN Conference on "Preventive Diplomacy: The Therapeutics of Mediation" (April 23-24, 1996, New York) some of the major problems concerning effective crisis prevention were addressed:

1. Lack of political will-a crisis that has not yet erupted is not generating either the pressures or the eventual rewards politicians normally need before making decisions and taking action. The absence of actual crisis visibility via media and TV ("CNN-factor") tends to reduce the sense of urgency needed for political decision makers. A still hidden crisis weakens the incentive for politicians and executive agencies to engage substantial financial, economic or even military resources in crisis avoidance. Last but not least, a still hidden crisis hampers the political will for either unilateral or multilateral action in preventive diplomacy, which in addition and as a rule, demands more patience than politicians are able to mobilize.

2. The sovereignty dilemma-preventive diplomacy to avoid the outbreak of an intrastate crisis often leads to intervention for and international solidarity with people in need. As such it can easily get into conflict with the principle of state sovereignty, which the international community is also bound to respect and protect. This tension between two conflicting goals in international affairs is an additional factor to considerably slowdown effective preventive action; as UN-Secretary General Boutros Boutros-Ghali stated in his address at the above mentioned UN Conference:

Failure to take effective preventive action is only rarely due to lack of early warning; the symptoms are usually there for all to see. What is too often lacking at present is a predisposition by the parties to accept third party assistance in resolving their dispute. Ways have to be found to persuade them, without infringing their sovereignty or other rights, that it is in their own interest to accept the help of the UN and other international players, rather than to allow their dispute to turn into armed conflict.

3. The limits of traditional diplomacy-traditional diplomacy tends to secretive procedures, to interest of the parties involved and of encouraging them to refrain from violent conflict. What is needed is a well-coordinated and fine-tuned mix of political, economic, social, developmental and eventually military measures to avoid conflict eruption and facilitate crisis management. Such a mix however requires mental readiness to accept division of labour, interdependence and crossfeeding between very often competing

\section{Any effective early warning system has to be directed to mobilize the political will for early action; that is for early decisions on concrete effective steps to get preventive diplomacy moving. Early warning systems must, hence, consider the practical problems and dilemmas of preventive diplomacy in view of overcoming them and facilitating the task of the executive agencies and governmental decision makers.}

problem and tension avoidance, to business as usual, to keep smiling and appeasement. It concentrates not only on quiet but also on silent diplomacy. Effective preventive diplomacy on the other hand can never be silent; it must address the critical issues directly, go to the roots of the conflict, use confidentiality as well as transparency and publicity to sound such credible alarm as to make crisis prevention work. Effective prevention has to do with leverage and deterrence; it is usually an edgy, not a smooth operation; it is the very opposite of appeasement.

4. There are rare cases like the one in 1995 in Burundi, where the US ambassador had the exceptional courage to personally organize a preventive press conference in order to make public some of the most barbarous atrocities that were going on in that country day by day and for which he held the Burundi government responsible.

5. The bureaucracy block-effective preventive diplomacy requires a balanced blend of incentives and disincentives with the aim of appealing to the enlightened self- ministries and departments in national administrations as well as between different governments, international organizations and INGO's. Deblocking bureaucratic obstinacies and rivalries or just streamlining overly complicated administrative procedures is therefore one of the major challenges which preventive diplomacy and its early warning instruments have to cope with.

Any effective early warning system has to be directed to mobilize the political will for early action; that is for early decisions on concrete effective steps to get preventive diplomacy moving. Early warning systems must, hence, consider the practical problems and dilemmas of preventive diplomacy in view of overcoming them and facilitating the task of the executive agencies and governmental decision makers.

These considerations have been very much on our mind regarding outline and leading criteria of our early warning project (FAST) for the Swiss MFA. The following elements for establishing an early warning system as mandated by the Swiss MFA seem crucial to us: 
- FAST has to be a system which can become functional and operational on a rather short term basis and at the same time be a system based on (computerized) early warning models and indicator clusters which lend themselves to constant refinement and adjustments; FAST is meant to be a scientifically developed instrument to be of immediate use to political practitioners and decision makers, not an academic exercise for professorial experimenting and speculation.

- FAST has to be a system of multidepartmental, multipurpose and multidirectional nature; the data and information to be monitored and the geographical areas to be covered have to satisfy the early warning requirements of different agencies in the MFA: on the one hand, the more globally-oriented political department, looking after Swiss interests worldwide (trade, investments, migration, terrorism, proliferation, etc.) and concentrating on the 53 OSCE states, especially the transition of ex-communist countries to democratic civil societies; on the other hand, the more narrow and third-worldfocused development cooperation agency, concentrating on some 16 focal countries with major foreign aid projects.

- FAST has to be an early warning chain-system going all the way from monitoring, collection and dissemination of information, up to analysis, evaluation, risk-assessment and finally presentation of policy options and scenarios credible enough to convince policymakers about the need for early action; it should be conceived as a bridge between crisis theatre and crisis management; it should be elaborated as a "pipeline"- or "flow chart"-system, in order to enhance institutionalized pressures, channel political decision making and thus prepare the ground for early preventive action.

- FAST has to be anchored and established outside the executive and administrative structures of the Foreign Ministry; yet, it still has to work and function in close collaboration and feedback-relation with authorized persons and staff from within the Ministry; the Swiss Peace Foundation, which has been mandated to work out the pilot project, could eventually very well be entrusted with the actual implementation, organization and daily management of the FAST-early warning system.

- FAST should be structured and equipped so as to monitor and collect different levels and types of data, based on the fact, that crisisand violence-breeding conflicts are dynamic processes, rooted in history and evolving in escalating or de-escalating phases: (1) background conditions of a crisis (historical, economic and social roots of the conflict, power and ethnic structures, cultural/civilizational particularities, etc.)); (2) intervening conditions (power struggle within the political leadership, increasing discrimination of certain social strata, etc.); (3) so called "accelerators" (repressive measures by the regime, violent incidents, sanctions, threats of international intervention, etc.) that change the nature of the crisis and propel it into a new, more or less violent phase.

We would like to list here some of the practical questions, which we are facing in our layout for the FAST-early warning pilot project on behalf of the Swiss Foreign Ministry. For some of these questions, the academic and research community might have at least partial answers already available; others will have to wait for the trial and error test of practical experience:

- Should FAST be built on global data base or should it be more focus oriented, that is restricted to focal points and countries of interest? What are the advantages and disadvantages of each one of these two approaches?

- What models do already exist to satisfy the multidepartmental and multidirectional needs of FAST, which has to provide three different sections of the Swiss MFA with an early warning instrument?

- Should FAST in its static part provide data (on-line) on a permanent basis or will periodical reporting be enough? Can the two concepts be. mixed?

- Should FAST be totally or overwhelmingly Swiss and self-made or should it plug into existing early warning networks that also work for other governmental customers? To what extent can non-Swiss early warning capacities be explored and utilized?

- Should FAST be open to all sources of information or should the early warning source material be collected on a selective basis? How and by which criteria should this selection be implemented?

- How should the out-of-government early warning center of FAST connect with the in-government structures of the Foreign Ministry? Is a special institutional link required or will case by case contacts do?

- What are the manpower requirements of such an out-of-government early warning center? What kind of specialists are needed for FAST on a permanent or a temporary basis?

- How much ground in the direction of political decision making should FAST cover without overloading and overcommitting itself? Should for instance the presentation of policy options in a given crisis be part of the early warning chain of FAST?

The setting-up of an early warning system like FAST provides fascinating insight into the interdependent worlds of international politics on the one hand and international science and research on the other. Doers and thinkers blend in intimate interaction. They are bound to coordinate and integrate their efforts, since early warning efforts without the thinkers will develop no roots and without the doers will bear no fruits. 